В. Ф. Балакин, В. Е. Машинистов, А. С. Коверя

Национальная металлургическая академия Украины, г. Днепр, Украина

Перспективная технология рециклинга радиоактивно загрязненного металла на ос нове его плавления

Предложена технология, которая позволит возвратить в промышленное производство большие объемы накопившегося радиоактивно загрязненного металла и создает условия для предупреждения экологических нарушений. В основе такой технологии лежит плавление загрязненного металла в печи индукционного типа без его предварительной частичной дезактивации и без принятия мер, способствующих переводу радионуклидов в шлак. Плавление загрязненного металла преобразует его из источника ионизирующего излучения с поверхностным распределением радионуклидов в источник с их объемным распределением, в результате чего гамма-излучение с поверхности выплавленного металла уменьшается в десятки - сотни раз. Показано, что критерием радиационной безопасности выплавленного металла является максимальное значение мощности гамма-излучения с его поверхности, при котором обеспечивается непревышение установленного лимита индивидуальной годовой эффективной дозы облучения.

Ключевые слова: радиоактивно загрязненный металл, рециклинг, дезактивация, плавление, облучение.
() В. Ф. Балакин, В. Е. Машинистов, А. С. Коверя, 2018
$\mathrm{P}$ адиоактивно загрязненный металл (РЗМ) образуется в ходе эксплуатации, ремонта, модернизации или демонтажа объектов ядерной отрасли. Загрязнение природными радионуклидами имеет место и в других производственных сферах, например газо- и нефтеперерабатывающей. Большие объемы РЗМ, образовавшиеся в результате аварии на Чернобыльской АЭС и в процессе ликвидации ее последствий, накоплены в зоне отчуждения Чернобыльской АЭС.

Находящиеся на поверхности загрязненного металла радионуклиды являются источниками ионизирующего излучения, опасного для биологических объектов. Поэтому для повторного использования РЗМ необходимо создать условия для того, чтобы индивидуальная эффективная доза облучения от находящихся на его поверхности радионуклидов не превышала установленный лимит дозы.

РЗМ представляет собой возобновляемый, причем многократно, источник сырья для металлургической промышленности, использование которого позволит значительно улучшить технико-экономические показатели ее работы. Успешное решение проблемы рециклинга РЗМ приведет к уменьшению объемов добычи и переработки минерального сырья, что будет способствовать предупреждению экологических нарушений, а также существенно уменьшит издержки в горнопромышленном комплексе.

Анализ литературных данных и постановка проблемы. На практике для возвращения в оборот РЗМ проводят дезактивацию его поверхности различными способами [1], что не всегда обеспечивает требуемую степень очистки изделий сложной конфигурации и к тому же сопровождается образованием больших объемов новых радиоактивных отходов (РАО). Это экономически нецелесообразный, трудоемкий и небезопасный для производственного персонала путь.

В настоящее время наиболее эффективным подходом к рециклингу РЗМ считается дезактивация методом переплава, основанная на плавлении загрязненного металла с целью перевода радиоактивных веществ в шлак. Металл плавят в электропечах с добавлением в шихту дезактивирующих компонентов, способствующих более полному выведению радионуклидов. Плавление РЗМ применяют с целью уменьшения количества подлежащих захоронению РАО и возврата в ограниченных объемах металла в промышленность [2-5].

Во многих случаях технологию плавки приходится усложнять, устанавливать дополнительное и сложное оборудование, что существенно понижает эффективность процесса переработки загрязненного металла и, как следствие, приводит к его существенному удорожанию.

На предприятии «ЭКОМЕТ-С» (г. Сосновый Бор, Россия) метод переплава используется на заключительном этапе процесса переработки металлических отходов, загрязненных радиоактивными веществами, с целью перевода их в шлак [6]. Обязательным элементом технологии переработки является предварительная дезактивация металлического сырья перед плавлением. Конечный продукт - слитки, которые в качестве вторсырья направляются в металлургическое производство. Данная технология, как утверждается, позволяет вернуть большую часть загрязненного металла после очистки в оборот для неограниченного использования. Образующиеся вторичные РАО, количество которых составляет не более $10 \%$ исходной массы загрязненного металла, переводятся в экологически безопасную форму, пригодную для транспортировки и захоронения.

Однако количество РЗМ, которое после переработки известными методами может повторно использоваться 
без каких-либо ограничений, остается чрезвычайно малым по сравнению с его объемами (не более 7 \%) [2], которые продолжают накапливаться в результате производственной деятельности ряда предприятий как ядерного, так и неядерного секторов.

Анализируя опыт эксплуатации плавильных печей и существующие технологические решения, в основе которых лежит метод переплава, обрашает на себя внимание тот факт, что и без принятия мер по выводу радионуклидов из металла уровень гамма-излучения с поверхности слитка намного ниже того, который был на поверхности загружаемого в печь РЗМ. При этом альфа- и бета-излучение, как и радионуклиды, не выходит за пределы выплавленного металла. Следовательно, в известных подходах не учитывается влияние ряда эффектов, сопровождающих плавление загрязненного радионуклидами металлургического сырья, на уровень радиационной безопасности выплавленного металла, а значит, необходимо более глубокого исследовать процессы при плавлении РЗМ с позиции их влияния на эффективную дозу, которая формируется излучением с поверхности слитка.

Цель статьи - предложить технологию рециклинга радиоактивно загрязненного металла на основе его плавления для промышленного использования.

Радиоактивно загрязненный металл как источник облучения человека. Для того чтобы металл, загрязнение которого радионуклидами привело к повышению уровня ионизирующего излучения (ИИ) с его поверхности, можно было использовать повторно, необходимо обеспечить его радиационную безопасность. С этой целью устанавливается система радиационно-гигиенических регламентов как для отдельного человека, так и общества в целом; в основе таких регламентов лежат рекомендации Международной комиссии по радиологической защите (МКР3). В соответствии с НРБУ-97 [7], основным критерием радиационной безопасности техногенного источника ИИ служит индивидуальная годовая эффективная доза внешнего облучения индивидуума, находящегося в зоне действия излучения источника, которая не должна превышать установленного лимита дозы. Для любого лица из населения (категория В) числовое значение годового лимита дозы ЛД ственного персонала (категория А) - 20 мЗв/год, причем в течение календарного года распределение дозы не регламентируется.

В данном исследовании учтены рекомендации, изложенные в публикации 103 МКР3 [8], которые систематизируют и дополняют указания по контролю облучения от источников ИИ, разработанные после ввода в действие НРБУ-97.

В общем случае дополнительная к природному радиационному фону доза облучения любого человека $E_{\text {доп }}$ равна сумме эффективной дозы внешнего облучения источником ИИ, накопленной за календарный год $\left(E_{\text {внеш}}\right)$, и ожидаемой эффективной дозы внутреннего облучения, обусловленной поступлением загрязнивших данный источник радионуклидов в организм того же человека за тот же период времени $\left(E_{\text {внутр }}\right)$ [9]:

$$
E_{\text {доп }}=E_{\text {внеш }}+E_{\text {внутр }} \text {. }
$$

Величина эффективной дозы $E_{\text {доп }}$ является количественной мерой радиационной опасности, исходящей от загрязненного радионуклидами объекта. Для обеспечения

\section{Окружающее пространство}

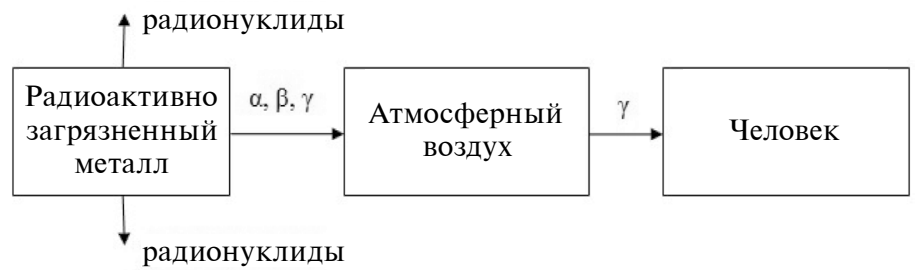

Рис. 1. Схема поступления ионизирующего излучения от радиактивно загрязненного металла к человеку

радиационной безопасности источника ИИ необходимо проанализировать вклад в дозу $E_{\text {доп }}$ каждого из возможных путей воздействия его излучения на отдельного человека.

Для нахождения количественной связи между характеристиками источника ИИ (загрязненный радионуклидами металл) и создаваемой им индивидуальной эффективной дозой воспользуемся рис. 1.

Исходным поражающим радиационным фактором являются радионуклиды, находящиеся на поверхности металла. При распаде радионуклидов испускается ИИ, которое распространяется от поверхности РЗМ через приземный слой атмосферы к человеку по прямой линии, соединяющей его с источником. Проникающая способность ИИ разных видов характеризуется длиной свободного пробега в веществе. Из всех видов излучения наибольшую опасность для человека представляет гамма-излучение (табл. 1): его пробег в воздухе равен сотням метров, оно способно проникнуть внутрь организма на большую глубину и воздействовать на внутренние органы. Таким образом, слагаемое $E_{\text {внеш }}$ в выражении (1) практически формируется только дозой гамма-излучения $E_{\gamma}$.

Таблица 1. Длина пробега ионизирующего излучения в веществе

\begin{tabular}{|c|c|c|c|}
\hline \multirow{2}{*}{ Вид излучения } & \multicolumn{3}{|c|}{ Длина пробега } \\
\cline { 2 - 4 } & в воздухе & в биоткани & в металле \\
\hline $\begin{array}{c}\text { Альфа-излу- } \\
\text { чение }\end{array}$ & $\begin{array}{c}\text { Несколько } \\
\text { сантиметров }\end{array}$ & $\begin{array}{c}\text { Не более } \\
100 \text { мкм }\end{array}$ & $\begin{array}{c}\text { Десятки } \\
\text { микромет- } \\
\text { ров }\end{array}$ \\
\hline $\begin{array}{c}\text { Бета-излу- } \\
\text { чение }\end{array}$ & $\begin{array}{c}\text { Несколько } \\
\text { метров }\end{array}$ & $\begin{array}{c}\text { Несколько } \\
\text { миллиме- } \\
\text { тров }\end{array}$ & $\begin{array}{c}\text { Несколько } \\
\text { миллимет- } \\
\text { ров }\end{array}$ \\
\hline $\begin{array}{c}\text { Гамма-излу- } \\
\text { чение }\end{array}$ & $\begin{array}{c}\text { Сотни мет- } \\
\text { ров }\end{array}$ & Более 10 мм & $\begin{array}{c}\text { Несколько } \\
\text { сантиметров }\end{array}$ \\
\hline \multicolumn{3}{|c}{}
\end{tabular}

Так как РЗМ - это открытый источник ИИ, то под воздействием атмосферных явлений радионуклиды бесконтрольно могут переходить в состав других источников ИИ (атмосферу, подстилающую поверхность, грунтовые воды и т. п.). Внутрь организма облучаемого человека радионуклиды попадают только из источников ИИ вместе с вдыхаемым воздухом, при потреблении воды и пищи, но не от загрязненного металла. Значит, слагаемое $E_{\text {внутр }}$ в выражении (1), которое учитывает вклад внутреннего облучения в дополнительной индивидуальной эффективной дозе, равно нулю. 
В результате радионуклиды, которые находятся на поверхности РЗМ, представляющего собой по отношению к облучаемому человеку внешний источник ИИ, могут формировать дозу $E_{\text {доп }}$ за счет только одной составляющей - гамма-излучения $E_{\gamma}$. При этом значение дозы $E_{\text {доп }}$ от радионуклидного состава загрязнения не зависит. Следовательно, годовую индивидуальную эффективную дозу внешнего облучения $E_{\text {доп }}$ можно оценить путем измерения мощности дозы гамма-излучения $P_{\gamma}$ с поверхности РЗМ и суммарной продолжительности облучения данного индивидуума $T_{\text {обл }}$ за один год:

$$
E_{\text {доп }}=P_{\gamma} \cdot T_{\text {обл }}
$$

Мощность гамма-излучения $P_{\gamma}$ уменьшается с удалением точки ее измерения от источника, так как увеличивается толщина поглощающего слоя атмосферы, через который распространяется излучение. Поэтому оцениваемая мощность имеет свое максимальное значение $P_{\gamma}^{\text {макс }}$ у излучающей поверхности, и доза облучения человека, находящегося у излучающей поверхности, будет наибольшей по сравнению с теми дозами, которыми одновременно облучатся другие люди в зоне действия излучения, созданного РЗМ.

Полученный в результате плавления РЗМ металл будет безопасным при выполнении неравенства

$$
E^{\text {макс }} \leq \text { ЛД }_{\mathrm{E}}
$$

где ЛД чивается радиационная безопасность РЗМ.

Если учесть, что значения годовой эффективной дозы и мощности гамма-излучения связаны между собой линейной зависимостью (2), соотношение (3) можно представить в виде

$$
E_{\gamma}^{\text {макс }} \leq P^{\text {доп }}
$$

где $P$ доп - допустимое значение мощности гамма-излучения.

Значение $P^{\text {доп } я в л я е т с я ~ д о п у с т и м ы м ~ у р о в н е м ~ у с р е д н е н-~}$ ной за год мощности гамма-излучения, который соответствует лимиту эффективной дозы при условии, что индивидуум подвергся только внешнему облучению от данного источника. Рдоп является производным нормативом от эффективной дозы и, следовательно, может использоваться в качестве единого критерия радиационной безопасности металла. Собственно, такой подход и применяется на практике. В металлургической промышленности металл считается радиационно безопасным, если мощность поглощенной дозы у его поверхности не превышает 0,2 мкГр/ч.

Если неравенство (4) не выполняется, необходимо принимать меры по обеспечению радиационной безопасности РЗМ с целью его рециклинга, что можно реализовать только одним путем: уменьшением мощности гамма-излучения с поверхности РЗМ до приемлемого уровня. Рассмотрим возможность решения этой задачи путем плавления РЗМ.

Плавление радиоактивно загрязненного металла с целью его дезактивации. Традиционный метод уменьшения уровня ИИ, создаваемого загрязненными радиоактивными объектами, - их дезактивация. Однако такой путь, как показывает практика, далеко не всегда эффективный и единственный. Уменьшить уровень ИИ, который создается загрязняющими металл радионуклидами, можно не только удалением их с загрязненной поверхности, но и воздействием на пути поступления радионуклидов и ИИ к отдельному человеку. Поскольку конечной целью дезактивации какого-либо объекта является исключение ИИ или уменьшение его уровня, всю совокупность действий по достижению данной цели на практике объединяют единым понятием «дезактивация». Оба указанных способа уменьшения уровня ИИ реализуются при плавлении РЗМ.

Плавление Р3М, не подвергавшегося предварительной дезактивации, является основным элементом технологии рециклинга, суть которой изложена в [10-13]. При плавлении радионуклиды, которые находились на поверхности металла, переходят в расплав и распределяются в его объеме равномерно. Таким же остается распределение радионуклидов и в выплавленном слитке. В итоге процесс плавления приводит к преобразованию открытого источника ИИ, каким был РЗМ, в закрытый источник, из которого радионуклиды не могут выйти в окружающую среду и попасть в организм человека. Следовательно, внутренний путь облучения человека данным источником полностью исключается. Что касается внешнего облучения, то за пределы слитка может выходить гамма-излучение только тех радионуклидов, которые находятся у поверхности металла в слое толщиной, равной нескольким сантиметрам; гамма-излучение всех остальных радионуклидов поглощается в металле полностью, а альфа- и бета-излучение не выходит за пределы объема металлического слитка. Таким образом, каким бы ни был объем металла, выплавленного из РЗМ, он является источником только гамма-излучения, причем его мощность не превышает некоторого максимального значения, зависящего как от энергии излучения радионуклида, так и от плотности металла. Уменьшение уровня ИИ за счет его поглощения в металле, в котором находятся источники излучения, можно условно назвать самодезактивацией.

При плавлении часть радионуклидов может переходить в шлаковую и газоаэрозольную составляющие продуктов плавки, что существенно уменьшает количество оставшихся в металле радионуклидов.

Никакие процессы обработки изделий из выплавленного металла не могут повысить уровень их радиационной опасности для биологических объектов. Безопасные уровни гамма-излучения с поверхности готовой продукции достигаются при настолько низких концентрациях радионуклидов в металле, что они никак не меняют его физические и химические свойства.

Таким образом, процесс плавления создает условия для получения из Р3М металла, пригодного для использования без каких-либо ограничений, в основном - за счет эффекта самодезактивации при объемном распределении радионуклидов в ИИ.

Характеристика продуктов плавки радиационно загрязненного металла как источников ионизирующего излучения. Основная цель плавления РЗМ - получение из него металла, удовлетворяющего нормам радиационной безопасности.

Рассматриваемый подход к обеспечению радиационной «чистоты» металла, полученного из РЗМ, защищен патентом Украины [14]. Его суть состоит в том, что суммарная активность вносимых в печь гамма-излучающих радионуклидов должна быть такой, чтобы мощность 


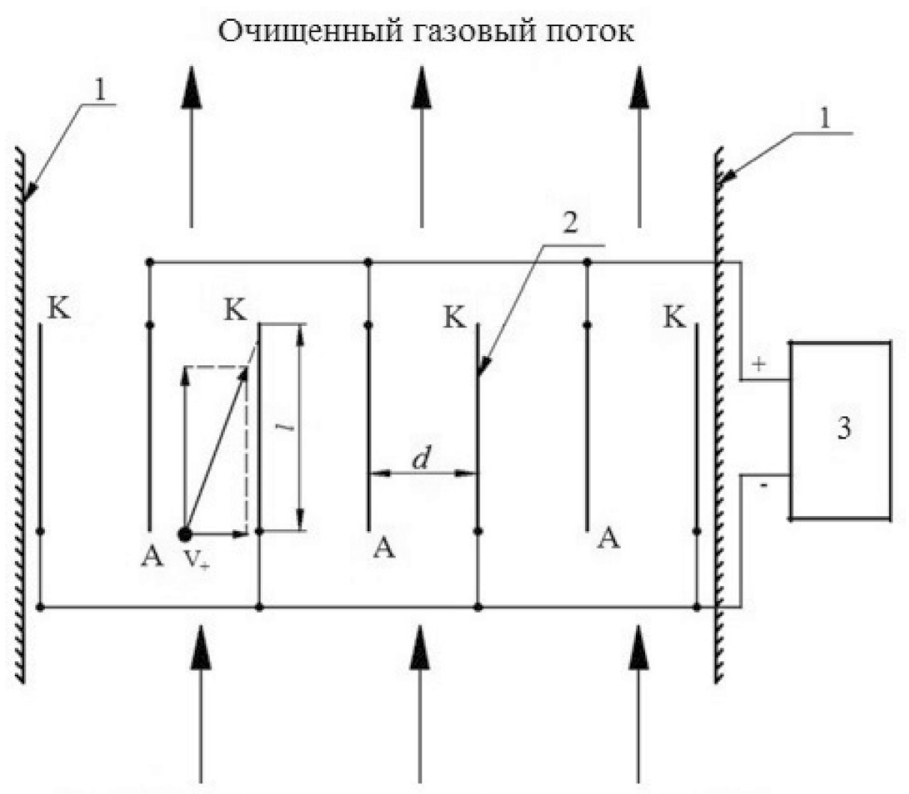

Загрязненный радионуклидами газовый поток

Рис. 2 Схема электрофильтра для очистки газоаэрозольных выбросов, загрязненных радионуклидами

гамма-излучения с поверхности готовой металлопродукции не превышала установленного нормативными документами значения. В [13] показано, что выполнение данного требования сводится к определению среднего значения мощности гамма-излучения на поверхности загрязненного металла, загружаемого в печь.

Выплавленный из РЗМ металл как источник ИИ может быть полностью освобожден от регулирующего контроля, если он одновременно будет отвечать при всех возможных реальных обстоятельствах критериям освобождения, изложенных в [7].

Проблемы, которые возникают при обращении с побочными продуктами плавки, аналогичны тем, которые изучались при сжигании в печах РАО в ходе многолетних испытаний на территории Чернобыльской зоны отчуждения и изложенных в [15]. Натурные эксперименты проводились с помощью лабораторной установки для термической переработки РАО из смеси разнородных материалов; радиационная обстановка соответствовала установленным критериям безопасности, неконтролируемое попадание радиоактивных веществ в окружающую среду исключалось. Использовавшиеся в данной лабораторной установке такие функциональные узлы, как система многоступенчатой очистки газоаэрозольных выбросов, система непрерывного радиационного контроля и контроля выбросов радионуклидов, могут быть включены в состав установки для плавления РЗМ.

Сопутствующие продукты плавки в металлургической печи - шлак и газоаэрозольная составляющая. Объем образовавшегося шлака составляет 5-10\% объема выплавленного металла. Как правило, его направляют на захоронение.

Поскольку плавление РЗМ происходит при высокой температуре, образуется большое количество мелкодисперсных частичек, содержащих радионуклиды, в составе газоаэрозольных выбросов. Для соблюдения допустимых уровней газоаэрозольных выбросов в атмосферу необходима многоступенчатая система очистки, эффективность которой может быть существенно повышена применением в качестве последней ступени очистки выбросов электрофильтра, описанного в [16, 17]. В основе предлагаемого способа лежит тот факт, что радионуклиды, являющиеся, как правило, металлами, находятся в окружающей среде в виде ионов. Поэтому газоаэрозольные выбросы можно очистить пропусканием загрязненного радионуклидами газа через поперечное постоянное электрическое поле, под действием которого положительно заряженные ионы движутся в направлении катода и накапливаются там. Схема установки, на которой реализуется предложенный способ очистки, представлена на рис. 2.

Электрофильтр встроен в газоход 1, поперечное сечение которого перекрывается системой пластинчатых электродов 2. Электроды длиной $l$ размещены на одинаковом расстоянии $d$ друг от друга и подключены к блоку электропитания 3. Аноды $A$ и катоды $K$ объединены между собой параллельно.

Практическое применение технологии рециклинга радиационно загрязненного металла на основе его плавления. Как показали теоретические исследования, рассматриваемый подход может быть реализован на металлургической плавильной печи, оборудованной надежной системой газоочистки и вытяжкой для предотвращения выделения в окружающую среду радиоактивных аэрозолей.

Для проведения исследований можно использовать дооборудованную индукционную печь емкостью $30-50$ кг. Этого количества выплавленного за одну плавку металла достаточно для объективного радиационного контроля как входного сырья, так и готовой продукции, а также для оценки радиационной обстановки в процессе плавки. Начинать эксперимент нужно с загрузки практически незагрязненного сырья, от плавки к плавке повышая его загрязненность радионуклидами, что сделает процесс практически безопасным и позволит своевременно вносить в него коррективы. При таком подходе за короткое время можно разработать приемлемую для широкомасштабного промышленного производства методику расчета максимальной удельной активности гамма-излучающих радионуклидов, которые могут быть загружены в плавильную печь, чтобы обеспечить возможность использования выплавленного металла и изделий на его основе без каких-либо ограничений, и отработать все компоненты технологии рециклинга РЗМ.

С целью моделирования происходящих при плавлении Р3М процессов можно воспользоваться, на наш взгляд, печами для переработки РАО на АЭС. Для этого предлагается вместе со сжигаемыми материалами загружать в печь металлы, температура плавления которых меньше, чем температура в печи.

\section{Выводы}

Как показали теоретические исследования, разработанная технология рециклинга радиоактивно загрязненного металла дает возможность вернуть его в промышленное производство в больших объемах. Основой предложенного подхода является плавление загрязненного металла в печи индукционного типа без предварительной частичной дезактивации и без принятия мер, способствующих переводу радионуклидов в шлак.

Плавление загрязненного металла преобразует его из источника ИИ с поверхностным распределением 
радионуклидов в источник с их объемным распределением. В результате уровень гамма-излучения с поверхности выплавленного металла уменьшается в десятки, а то и сотни раз, что создает условия для получения радиационно безопасного металла, пригодного для использования без каких-либо ограничений. При плавлении часть радионуклидов переходит в шлак и газоаэрозольную фазу, что способствует повышению уровня безопасности выплавляемого металла.

Показано, что критерием радиационной безопасности выплавленного металла является максимальное значение мощности гамма-излучения с его поверхности, при котором обеспечивается непревышение установленного лимита индивидуальной годовой эффективной дозы облучения.

Применение данной технологии позволит возвратить в промышленное производство большие объемы накопившегося радиоактивно загрязненного металла и создает условия для предупреждения экологических нарушений.

\section{Список использованной литературы}

1. Ампелогова Н. И., Трапезников А. А. Дезактивация в ядерной энергетике. М., 1982. 256 с.

2. Лампард Д., Хиллис К. Переплавка радиоактивного металлолома. Атомная техника за рубежом. 2007. № 3. С. 27-30.

3. Copeland G. L., Heshmatpour B. Decontamination of TRU Contaminated Metal Waste by Smelting Refining. Transactions of the American Nuclear Society. 1981. № 38. P. 193-195.

4. Гуменюк В. И., Ломасов В. Н., Моторный А. В., Коробицин А. Р. Технология плавления радиоактивного металла с целью перевода основной части радионуклидов в шлак. Науч.-техн. ведомости Санкт-Петербургского государственного политехнического университета. 2013. № 1. С. 286-291.

5. Бережко Б. И., Горынин В. И., Никишин Г. Д., Хохлов А. А. Утилизация радиоактивных металлических отходов методом переплава. Вопросы материаловедения. 1995. № 2. С. 74-77.

6. Черемисин П. И. Обращение с металлическими отходами, загрязненными радиоактивными веществами. Рециклинг отходов. 2008. № 2(14). С. 2-5.

7. Норми радіаційної безпеки України (НРБУ-97). Державні гігієнічні нормативи. К., 1998. 135 с.

8. Публикация 103 Международной Комиссии по радиационной защите (МКРЗ). Пер. с англ. / Под ред. М. Ф. Киселева и Н. К. Шандалы. М. : Изд. ООО ПКФ «Алана», 2009. 344 с.

9. Ильин Л. А., Кириллов В. Ф., Коренков И. П. Радиационная гигиена. М., 2010. 384 с.

10. Mashinistov V. Ye., Galkin O. F. Technology for utilization of the metal contaminated with radioactivity at the enterprises of metallurgy. Metallurgical and Mining Industry. 2015. No. 2. P. 277-281.

11. Машинистов В. Е., Галкин О. Ф. Оценка радиационной обстановки при утилизации радиоактивно загрязненного металла с использованием эффекта самодезактивации. Metaljourna.l URL: https://www.metaljournal.com.ua/assessment-of-the-radiationsituation-in-the-disposal-of-radioactively-contaminated-metal-usingself-deactivation-effect (дата обращения 06.02.2018).

12. Balakin V., Mashinistov V., Galkin O. Practical aspects of utilization of the radioactively contaminated metal in metallurgical plants. Metallurgical and Mining Industry. 2015. No. 4. P. 307-311.

13. Balakin V., Mashinistov V., Galkin O., Bilan K. Technology of recycling radioactively contaminated metal by the method of melting. Eastern-European Journal of Enterprise Technologies. 2016. No. 4/5(82). P. $31-37$.

14. Спосіб утилізації радіоактивно забрудненого металобрухту: пат. № 109157 Україна: МПК (2015.01) G $21 \mathrm{~F} \mathrm{9/32,} \mathrm{А} 62$ D 3/32, В 09 В 3/00, С 22 В 7/00, С 22 В 9/00 / Машиністов В. Є., Галкін О. Ф.; заявник і патентовласник Національна металургійна академія України. № а2013 06522; заяв. 27.05.2013; опубл. 27.07.2015, Бюл. № 14.
15. Верюжський Ю. В., Гринько О. М., Токаревський В. В. Радіаційна безпека спалювання радіоактивних відходів, забруднених цезієм. Ядерна та радіаційна безпека. 2017. № 1(73). С. 66-72.

16. Спосіб очищення промислових газоподібних викидів від радіонуклідів: пат. № 114568 Україна: МПК G 21 F 9/02, В 03 С 3/08, В 01 J 19/08 / Машиністов В. Є., Алпаев Є. М., Кобзарь О. Р.; заявник і патентовласник Національна металургійна академія України. № a2015 12993; заяв. 29.12.2015; опубл. 26.06.2017, Бюл. № 12.

17. Машинистов В. Е., Алпаев Е. Н., Кобзарь О. Л. Очистка промышленных газообразных выбросов от радионуклидов электростатическим полем. Перспективні напрямки світової науки : Зб. статей учасників 37-ї Всеукр. наук.-практ. конф. «Інноваційний потенціал світової науки - ХХІ сторіччя». Запоріжжя, 19-22 квітня, 2016. T. 2. C. $28-30$.

\section{References}

1. Ampelogova, N. I., Trapeznikov, A. A. (1982), "Decontamination in Nuclear Power Engineering" [Dezaktivaciya v yadernoj energetike], Moscow, 256 p. (Rus)

2. Lampard, D., Hillis, K. (2007), "Remelting of Radioactive Scrap Metal" [Pereplavka radioaktivnogo metalloloma], Atomic technology abroad, No 3, pp. 27-30. (Rus)

3. Copeland, G. I., Heshmatpour B.. (1981), "Decontamination of TRU - Contaminated Metal Waste by Smelting Refining”, Transactions of the American Nuclear Society, No 38, pp. 193-195.

4. Gumeniuk, V.I., Lomasov V.N., Motorny A.V., Korobitsyn A.R. (2013), "Technology of Melting of Radioactive Metal for Transferring the Main Part of Radionuclides to the Slag" [Tekhnologiia plavleniia radioaktivnogo metalla s tseliu perevoda osnovnoy chasti radionuklidov v shlak], Scientific and technical bulletins of the Saint Petersburg State Polytechnic Universit, No 1, pp. 286-291. (Rus)

5. Berezhko, B. I., Gorynin V. I., Nikishin G. D., Khokhlov A. A. (1995), "Recycling of Radioactive Metal Waste by Remelting" [Utilizacija radioaktivnyh metallicheskih othodov metodom pereplava], Issues of Materials Science, No 2, pp. 74-77. (Rus)

6. Cheremisin, P. I. (2008), "Handling of Metal Waste Contaminated With Radioactive Substances" [Obrashhenie s metallicheskimi othodami, zagryaznennymi radioaktivnymi veshhestvami], Waste Recycling, No 2 (14), pp. 2-5. (Rus)

7. NRBU-97 Radiation Safety Standards of Ukraine. State Health and Safety Srandards [Normy radiatsiinoi bezpeky Ukrainy (NRBU-97). Derzhavni hihiienichni normatyvy], Kyiv, 1998, 135 p. (Ukr)

8. Kiselev, M. F., Shandala N. K. (2009), Annals of the International Commission on Radiological Protection (ICRP) [Publikatsiia 103 Mezhdunarodnoi Komissii po radiatsionnoy zashchite (MKRZ)], Moscow, 344 p. (Rus)

9. Il'in, L. A., Kirillov, V. F., Korenkov, I. P. (2010), "Radiation Hygiene" [Radiatsionnaia gigiena], Moscow, 384 p. (Rus)

10. Mashinistov, V. Ye., Galkin, O. F. (2015), "Technology for utilization of the metal contaminated with radioactivity at the enterprises of metallurgy", Metallurgical and Mining Industry, No. 2, pp. 277-281.

11. Mashinistov, V. Ye., Galkin, O. F. (2015), "Assessment of the radiation situation in the disposal of radioactively contaminated metal using self deactivation effect" [Ocenka radiacionnoj obstanovki pri utilizacii radioaktivno zagryaznennogo metalla s ispolzovaniem effekta samodezaktivacii], Metaljournal, Available at: URL: http:// www.metaljournal.com.ua/Assessment - of - the - radiation-situationin-the-disposal-of-radioactively-contaminated-metal-using-selfdeactivation-effect (06.02.2018) (Rus)

12. Balakin, V., Mashinistov, V., Galkin, O. (2015), "Practical aspects of utilization of the radioactively contaminated metal in metallurgical plants", Metallurgical and Mining Industry, No. 4, pp. 307-311.

13. Balakin, V., Mashinistov, V., Galkin, O., Bilan, K. (2016), "Technology of recycling radioactively contaminated metal by the method of melting", Eastern-European Journal of Enterprise Technologies, No 4/5 (82). pp. 31-37.

14. Mashinistov, V. Ye, Galkin, O. F. (2015), "Method of utilization of radioactive contaminated scrap" [Sposib utilizatsii radioaktyvno 
zabrudnenogo metalobruhtu], Patent UA 109157 Published in Bulleting No 14. (Ukr)

15. Veruzhsky, Yu. V., Grinko A. M., Tokarevsky V. V. (2017), "Radiation Safety for Incineration of Radioactive Waste Contaminated by Cesium" [Radiatsiina bezpeka spaliuvannia radioaktyvnykh vidkhodiv, zabrudnenykh tseziem], Nuclear and Radiation Safety, No 1 (73), pp. 66-72. (Ukr)

16. Mashinistov, V. Ye, Alpaev, Ye. M., Kobzar, O. R. (2017), "Method of purification of industrial gaseous emissions from radionuclides" [Sposib ochishchennia promyslovykh gazopodibnykh vykydiv vid radionuklidiv], Patent UA 114568 Published in Bulleting No 12. (Ukr)

17. Mashinistov, V. Ye, Alpaev, Ye. M., Kobzar, O. R. (2016), "Purification of industrial gaseous emissions from radionuclides by electrostatic field" [Ochistka promyshlennykh gazoobraznykh vybrosov ot radionuklidov elektrostaticheskim polem], Perspective directions of world science, Collection of articles of participants of the thirtyseventh All-Ukrainian scientific-practical conference "Innovative potential of world science - XXI century", Zaporozhye, 19-22 April, V. 2, pp. 28-30. (Rus)

\section{В. Ф. Балакін, В. Є. Машиністов, А. С. Коверя}

\section{Перспективна технологія рециклінгу радіоактивно за- брудненого металу на основі його плавлення}

Запропоновано технологію, яка дасть змогу повернути в промислове виробництво великі обсяги накопиченого радіоактивно забрудненого металу і створює умови для попередження екологічних порушень. В основі такої технології лежить плавлення забрудненого металу в печі індукційного типу без його попередньої часткової дезактивації та без вжиття заходів, що сприяють переведенню радіонуклідів в шлак. Плавлення забрудненого металу перетворює його з джерела іонізуючого випромінювання з поверхневим розподілом радіонуклідів у джерело з їх об'ємним розподілом, внаслідок чого гамма-випромінювання з поверхні виплавленого металу зменшується в десятки - сотні разів. Показано, що критерієм радіаційної безпеки виплавленого металу $є$ максимальне значення потужності гаммавипромінювання з його поверхні, при якому забезпечується неперевищення встановленого ліміту індивідуальної річної ефективної дози опромінення.

Ключові слова: радіоактивно забруднений метал, рециклінг дезактивація, плавлення, опромінення.

\section{Balakin, V. Mashinistov, A. Koveria}

\section{Perspective technology of recycling of radioactive contaminated metal based on its melting}

Melting of the radioactively contaminated metal converts it as a source of ionizing radiation from a surface distribution of radionuclides into the source with their volume distribution. From the surface of the melted metal gamma radiation of a part of radionuclides is emitted, which are in its scope. Alpha and beta radiation are absorbed completely in the metal.

To obtain a radiation-safe metal it is necessary that the amount of gamma-emitting radionuclides, which are loaded into the furnace together with the charge, did not exceed the established allowable level.

The radiation safety criterion of the melted metal is the maximum value of the gamma radiation power from its surface, the established limit of the individual annual effective radiation dose is not exceeded.

There is a need for experimental verification of theoretical results was obtained. The use of this technology will allow the return to industrial production of large amounts of accumulated radioactively contaminated metal and creates conditions for the prevention of environmental violations.

Keywords: radioactive contaminated metal, recycling, decontamination, melting, irradiation

Получено 22.02.2018. 